CORPORATE PERCEPTIONS OF JOB SATISFACTION AND EDUCATIONAL NEEDS

$$
\text { by }
$$

C. Elaine McCoy

The Ohio State University

Department of Aviation

September 1986

Submitted to:

University Aviation Association 


\title{
CORPORATE PERCEPTIONS OF JOB SATISEACTION AND EDUCATIONAL NEEDS
}

\author{
C. Elaine McCoy \\ The Ohio State University \\ Department of Aviation
}

During the winter of 1986, The Ohio State University Department of Aviation conducted a survey of randomly selected National Business Aircraft Association members. The survey served two explicit purposes (1) addressing the need for information to be used in the design of a course at OSU in corporate flight operations; and (2) assessing the needs of the industry for workshops and seminars in communication and management.

Direct information from corporate flight departments was sought to insure that the practical concerns of the corporate pilot or flight department manager be combined with organizational communication and management strategies tailored to the specific needs of the industry. This information was gathered through a series of scaled responses, and through closed and open ended questions. Industry cooperation and support has been excellent. The questionnaire's design provides insight into the perceptions of corporate pilots and managers regarding a number of factors that pertain to their degree of job satisfaction.

Public attention regarding aviation continues to focus on the airlines. Expansion, collapse, takeovers, hires, furloughs, unions, and routes all receive media attention. Primarily through the media, the general public and many prospective aviation professionals have become aware of the pilot shortage and the projected continued hires by major lines. Even among many commercial pilots the traditional goal continues to be attaining a major airlines captain slot despite the two-tier pay scales and changing benefits.

The rites of passage for a non-military pilot to build experience traditionally consisted of a progression from flight instructor to Part 135 then to corporate or to regionals then to majors. Those entering the corporate market have tended to remain in it. The corporate market on the surface seems healthy. The NBAA reports an increase in member aircraft $(5,547)$ and corporate membership $(2,941)$ in 1985. Except for 1983, membership shows an approximate growth of $10 \%$ per year. Company loyalty is often high, although conditions in corporate flight departments are known to vary greatly. What is there about the corporate arena that allows it to retain high time experienced professionals who have one of the best safety records in the business? Is it in the best interest of the industry that corporate aviation be such a well kept secret?

This study only provides an introduction to such questions. The paper examines those aspects of the OSU survey results which indicate the degree of satisfaction that survey respondent corporate managers and pilots exhibit regarding their perceptions of (1) their own company compared with other corporate flight 
operations; and (2) their position in their own company compared with a similar position with a major airlines. Those educational needs identified by the NBAA members as beneficial to either students soon to be operating in the corporate environment or to individuals already in the field are briefly addressed as well. Additional information obtained through follow-up in-person and telephone interviews is included. Respondent anonymity is maintained.

\section{The surver}

The survey consists of a cover letter and a three page questionnaire (see Appendix A). The letter states the two-fold purpose of the survey and assures participants of anonymity. Within each envelope the corporation received were two questionnaires. The recipient was requested to provide one to the Chief Pilot and one to the Chief Pilot's organizational superior.

The initial nine items are demographic in nature and pertain to the respondent's position, the number of personnel for whom $s /$ he is responsible, number of aircraft, flight certificates, mechanic certificates, flight time, age, sex, and whether the company is a Part 135 certificate holder. Of particular interest was the position of the respondent indicated as Chief Pilot, Manager, Both, or Other.

A two-part job satisfaction scale follows. Part I, having fifteen items, asks the respondent his/her perception of their own flight department compared with other corporate departments. Part II consists of twelve items duplicating twelve items in Part I and asks the respondent to compare his/her current position with a similar position with a major airlines. Three of the initial set were deemed inappropriate in the airlines response categories.

Two subsets of questions followed. The first directed at pilots ( 5 items) and the second at managers ( 6 items).

Two final open-ended questions solicited information concerning (1) interest in professional seminars, (2) topics for those seminars, and (3) topics deemed most beneficial for undergraduate students.

At the conclusion of the questionnaire, a space was provided for voluntary signatures and phone numbers. Respondents indicated whether or not they could be contacted for further information.

The participants

All participants were randomly selected within categories from the National Buisness Aircraft Association Directory. Categories and restrictions were as follows:

All participants were businesses based in the United States;

A minimum of two corporations from each state were selected;

A minimum of 20 corporations having less than 5 aircratt; and

A minimum of 20 corporations having 15 or more aircraft. 
The balance of the initial mailing of 200 envelopes ( 400 questionnaires) was random without consideration for category. A second mailing of 41 additional envelopes ( 82 questionnaires) focused on additional Ohio area companies.

Approximately twenty-one fercent oj the questionnaires were returned. Fifty-two per cent of active responses indicated a willingness for further discussion and exchange of information.

Profile of respondents

The typical respondent is a male, 36-50 years of age, with more than 5000 hours of filight time and an ATP.

\section{RESPONDENT PROFILE}

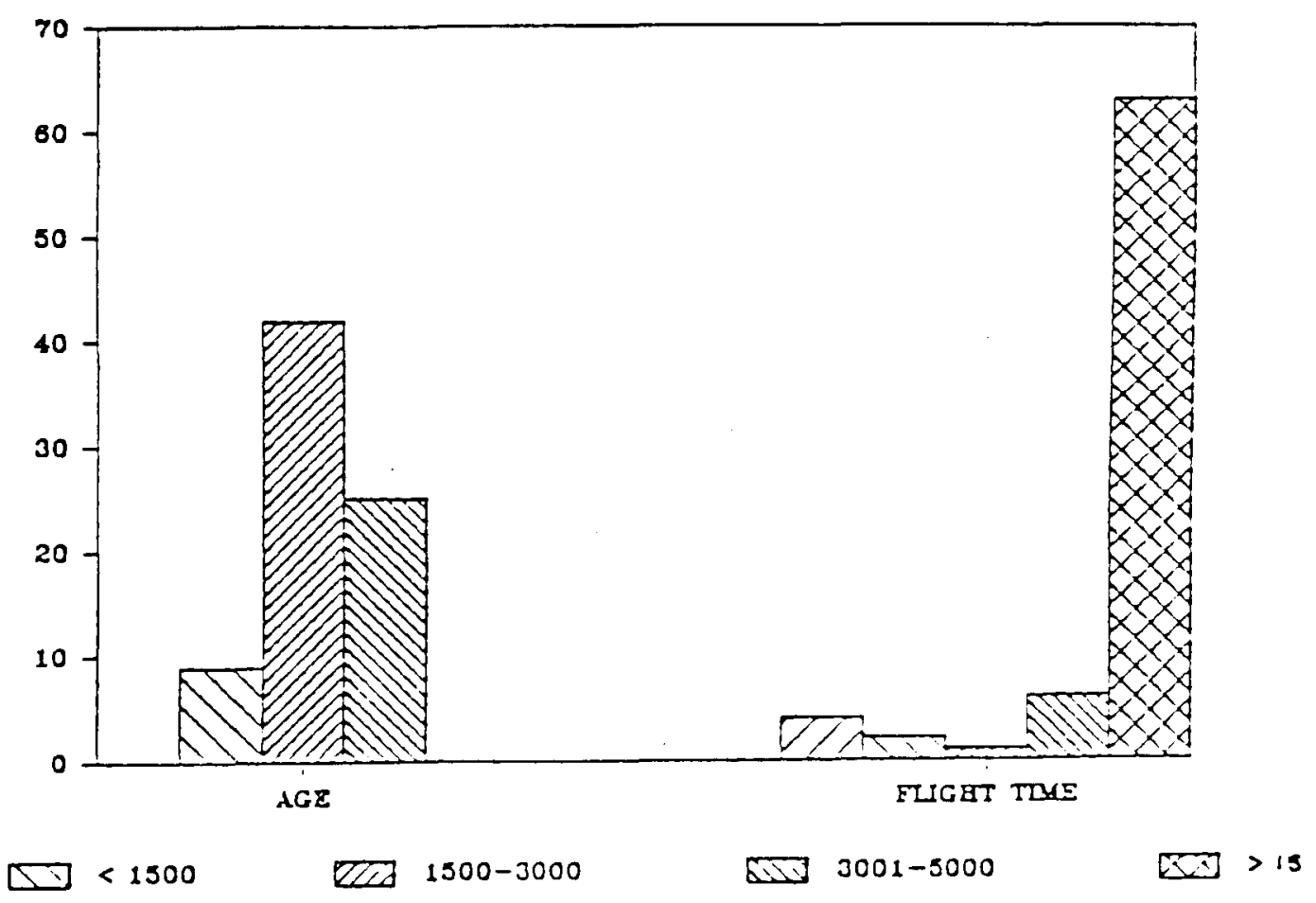




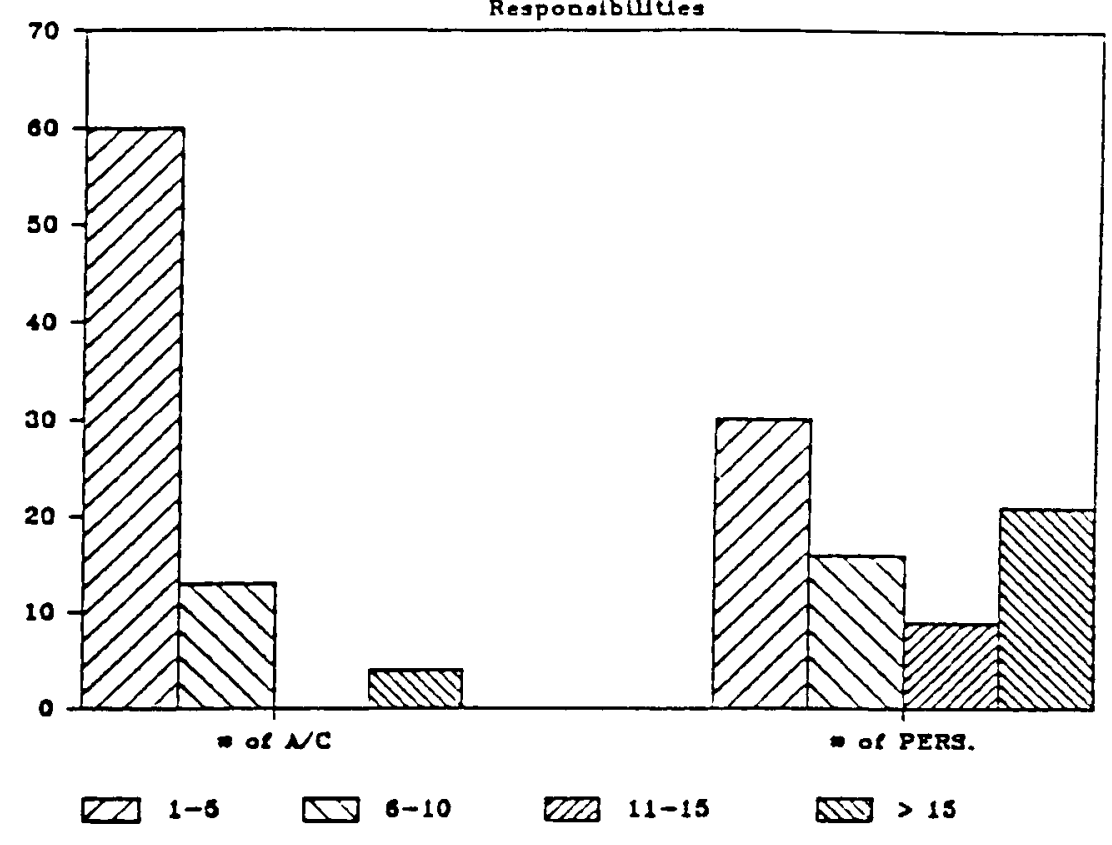

Distribution was fairly even for Chief Pilot, Manager, and Both categories. All respondents are male.

\section{Respondent Title}

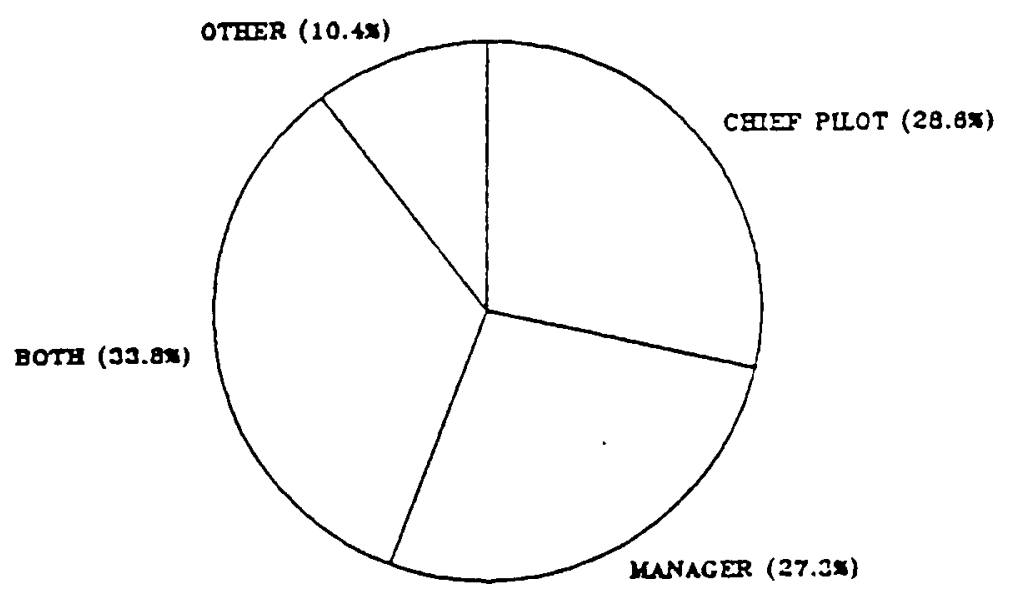


Results: Job Satisfaction

The survey results indicate that corporate pilots and managers have a high degreg of job satistaction. They consistently rated their own company as excellent or good--better than average--compared with other corporate flight departments. The home company was highly rated in terms of: salary, $86 \%$ (of respondents rating it excellent or good); fringe benefits, $81 \%$; schedule $74 \%$; rest $78 \%$; free time $64 \%$. However, when comparing their own companies to comparable airlines positions corporate positions fared less well. On salary only $41 \%$ rated the company better; on fringe $41 \%$; on schedules $49 \%$; rest, $61 \%$; free time, 45\%. These comparisons are noted on the following bar graphs labeled "Respondent Comparisons." These bar graphs give raw number comparisons for the categories indicated only for the better than average or positive responses. In each topic area the home company compared well with other corporations, and less favorably with airlines positions. For example, looking at the presentation of respondent comparisons concerning "Salary" on the bar graph, sixty respondents perceive their own company as Excellent or Good compared to other corporate flight departments. When the respondents are asked to compare their own companies with similar airlines positions only thirty-three rank the home company as Excellent or Good. By inference, the airlines are perceived to be more competitive in terms of salary. In areas concerning stability, co-workers, autonomy, and aircraft maintenance, corporate and airlines positions were both very positive and closely rated.

\section{Respondent Comparisons}

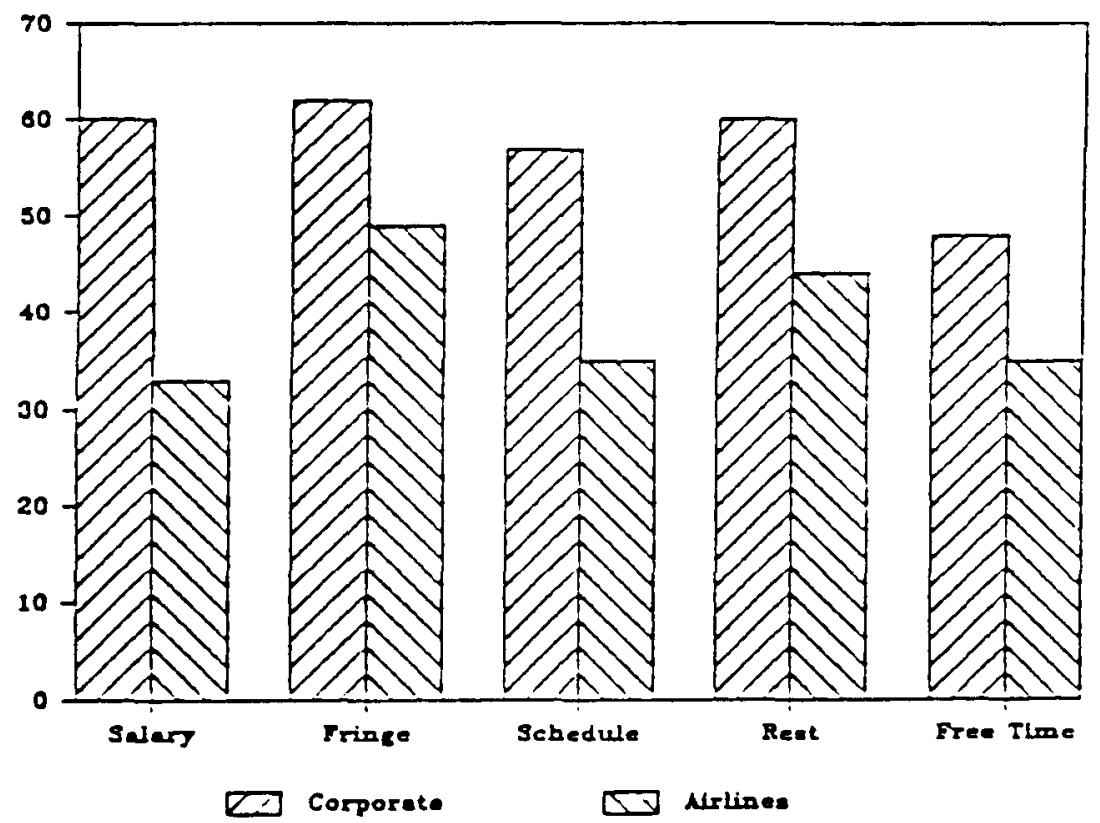




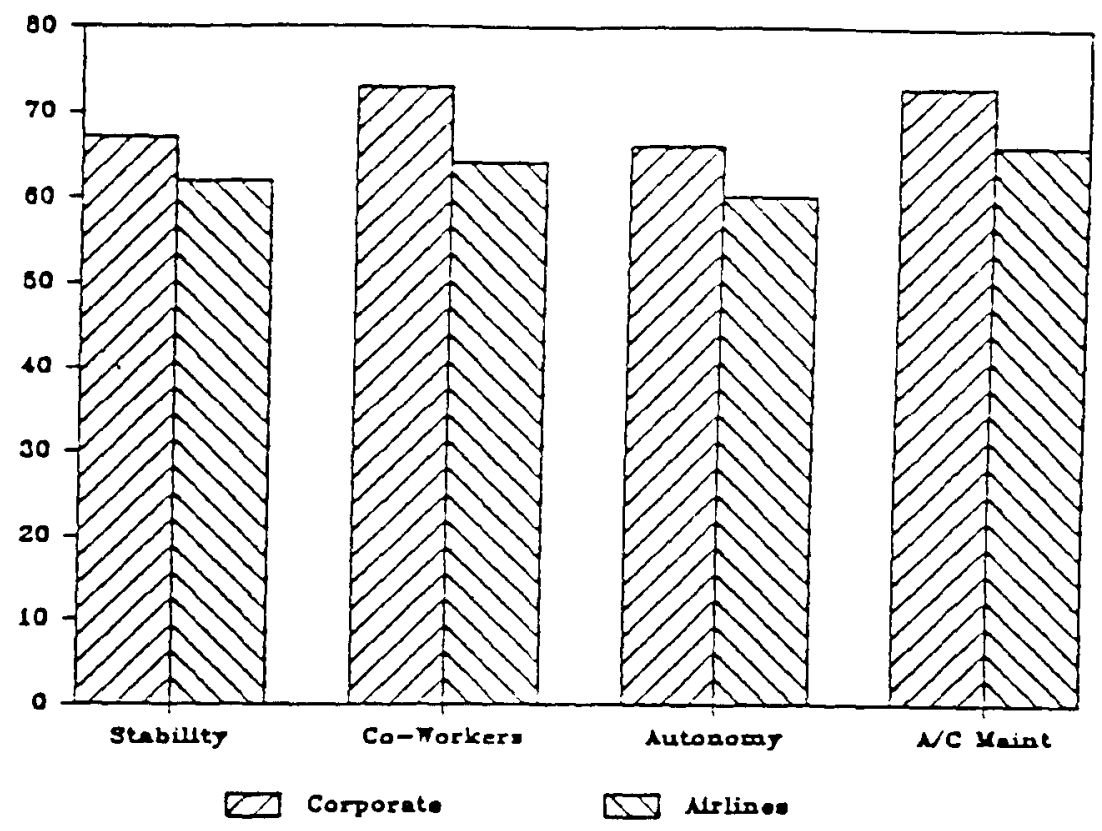

Terminology. Responses incorporate certain understandings of the terms used in the categories and these word-meaning fields can differ greatly. "Airlines" indicates Part 121 scheduled major carriers. "Rest," for example then, for an airlines pilot generally is scheduled time off-duty. Duty time consists of a fairly constant busy day. Corporate pilots who rated their own "rest" as less adequate, often wait for several hours at destinations or spend portions of duty days at the hanger. That time can be characterized either by the boredom of waiting or by the tension associated with aircraft or weather or passenger problems. Such time, indeed, is not "rest," and it differs from the flight schedule of the airlines who have canned flight plans, weather departments, etc. The same corporate pilots may fly constantly throughout the next day criss-crossing the country with very little "rest" of any kind. The two positions have different "workstyles" that are at times difficult to translate equitably.

While the scaled ratings of perceptions of airlines positions would suggest that airlines positions would be preferable, in response to the question to pilots, "Are you considering flying for an airlines?" only two answered "yes" giving pay, travel benefits, and family as reasons. One of these respondents is 23-35, with an ATP and 5000+ hours. The other is 36-50, with an ATP and $5000+$ hours. Only one other response even mentioned considering a flying job with another company.

A closer look at the responses across the rating scale that includes the negative evaluations is provided for "Salary," "Schedule," "Fringe Benefits," and "Free Time." These categories elicited the greatest variation in degree of satisiaction in the comparison of corporate life with perceived airlines positions. 
Respondent Comparisons

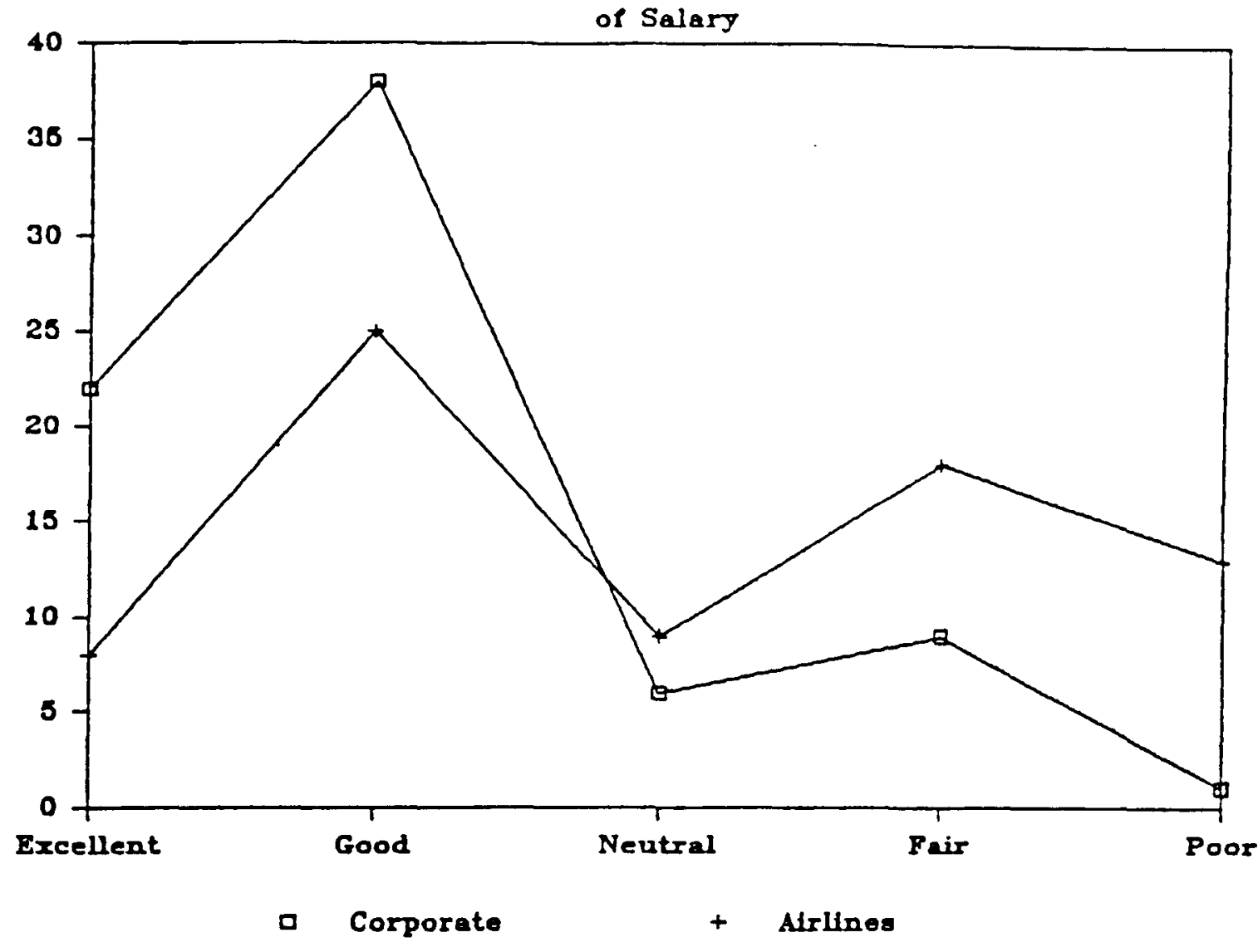

Respondent Comparisons

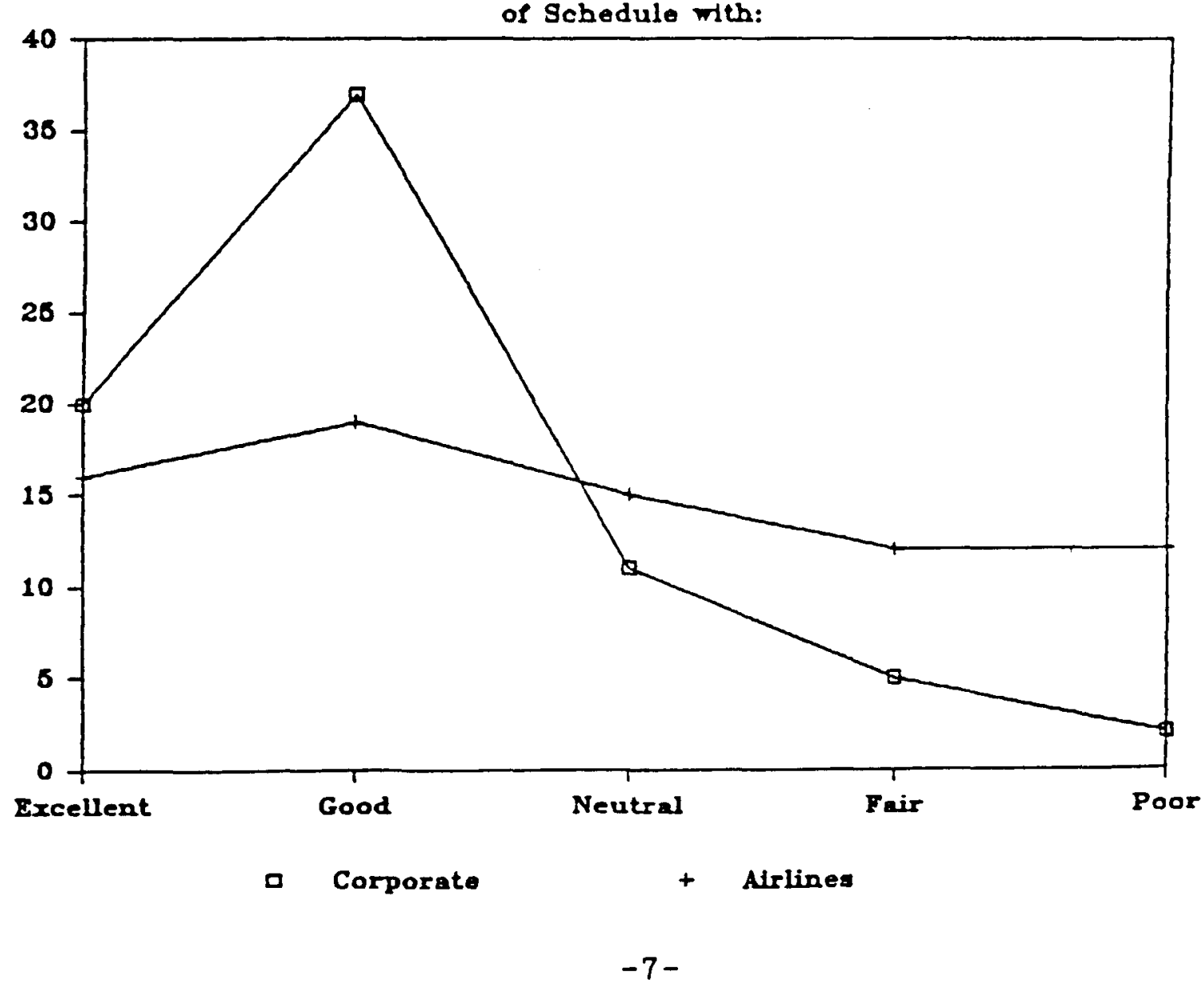


Respondent Comparisons

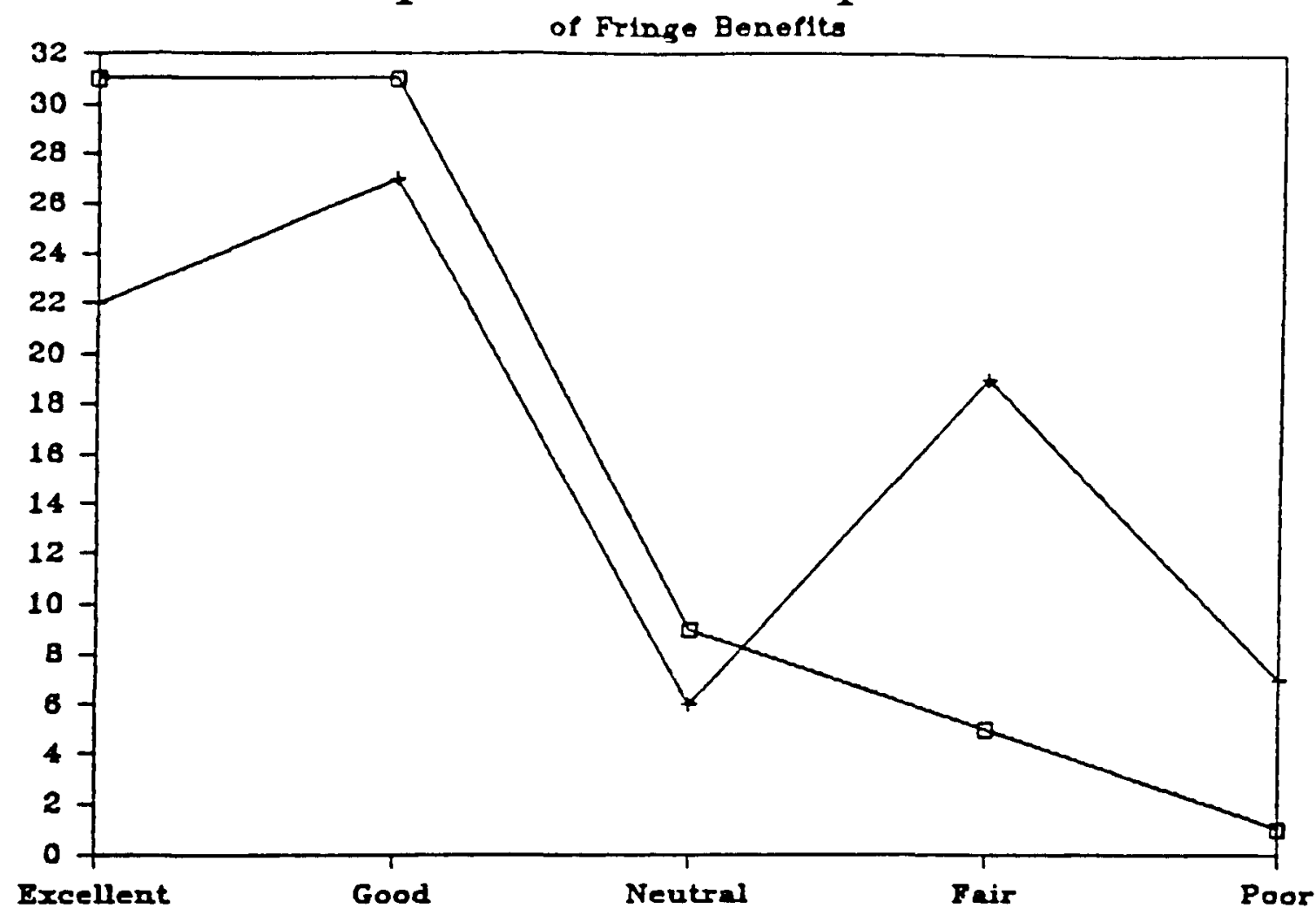

a Corporate + Airines

Respondent Comparisons

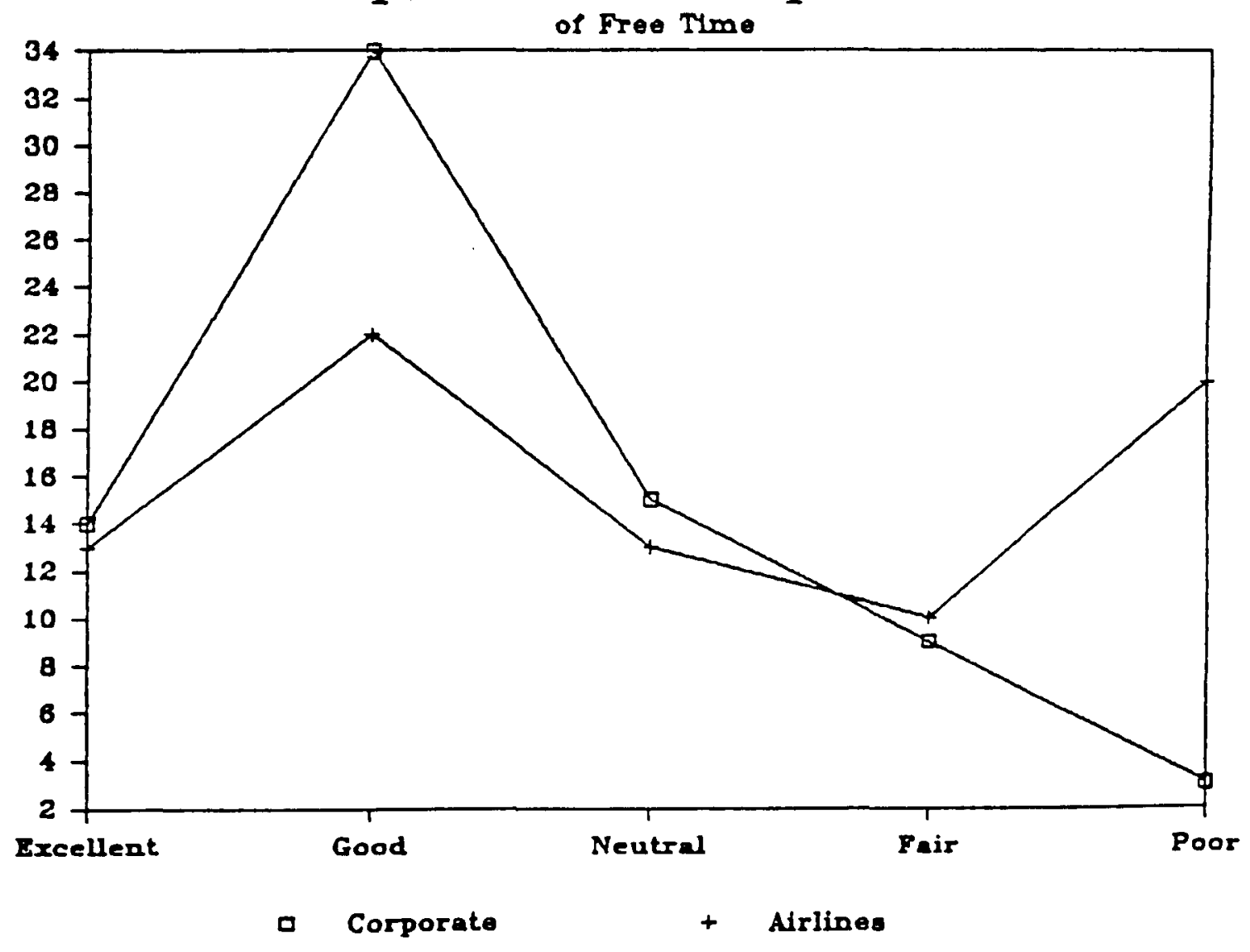


Respondents were strongly affirmative of their own company's competiveness with regard to each of these areas when compared with other corporations. As these line graphs indicate, however, the division was more evenly divided between those indicating positive and negative comparisons of their position when compared with an airlines.

The comparison of this information with those responses to the question of considering flying for an airlines, $2.5 \%$ affirmative, seems inconsistent. A return to the profile of respondents may help explain this. Not all respondents are professional pilots. A small number are strictly management positions. Approximately 5\% indicated no flight certificates, $9 \%$ Commercial, and $83 \%$ ATP. More importantly, pilots established in one aviation system may well be hesitant to leave for the bottom of a seniority list in a new one. While most pilot respondents have ample flight experience for airlines positions, $82 \%$ having more than 5000 hours, age and the career experience that it implies must be considered as well. While $55 \%$ are $36-42$, another $32 \%$ are between $51-65$.

At this time, pilots with both experience and age are being hired by airlines, but after years of working in one aviation "system" and becoming accustomed to a life/workstyle, not many may actually wish to give up their position with a company. That personal decision would not preclude them from rating their corporate position lower than airlines since in their perception and to the best of their knowledge had they followed the airlines track when they started they believe that a comparable current airlines position would provide them with better salary, fringe benefits, free time, etc. Pilot perceptions concerning airlines often mix actual knowledge obtained from airlines pilots with a somewhat mythical image of the \#1 Seniority Captain and "having made it." During the years that many of these respondents chose their career path, a multitude of ex-military pilots competed for positions with the majors while others chose to go into corporate. Non-military aspirants faced an extremely competitive market.

Increasing management responsibility also tends to discourage transfer to airlines positions. Twenty-two percent of the respondents are responsible for six or more aircraft and sixty percent are responsible for a staff of six or more.

Interestingly, perceptions of relative autonomy favored the airlines, but only slightly. While the supervision, care and overall involvement of the corporate pilot with his specific aircraft is more apparent in many aspects, the fact that PIC responsibilities make members of both pilot groups the final authority in the cockpit may serve to nullify other differences. One respondent reflects an attitude heard at times in general discussion that corporate pilots often indicate a pride and almost elitism in having corporate responsibilities compared with "bus drivers" as some describe airlines pilots. This attitude does not evidence itself in the specific response categories of this survey. Corporate pilots, as another respondent noted, often complain of less overall autonomy in that being on call for 
flights disrupts any personal plans and that is perceived as a corporate invasion into homelife. This is one area that varies with the flight department. Some operations provide pilots a month advance notice with Monday through Friday flight schedules.

Airlines autonomy is seen linked with seniority in that seniority brings the ability to choose aircraft, routes and therefore schedule, and even flight crews.

Perceptions of supervisors, coworkers, and employees indicates satisfaction and respect. Additionally, both pilots and managers indicate that executives have a realistic grasp of the job of those involved in the flight department (62\%). Managers believe that pilots do have a clear understanding of the fight department's position in the company (93\%).

Management choice in hires

According to the survey, management still wants pilots who fly only. Fifty-eight percent indicated this choice. Sixteen percent want pilots with mechanic certification, and twenty-six percent would like pilots who can work in other capacities for the company.

\section{Management Desires pllots Tho:}

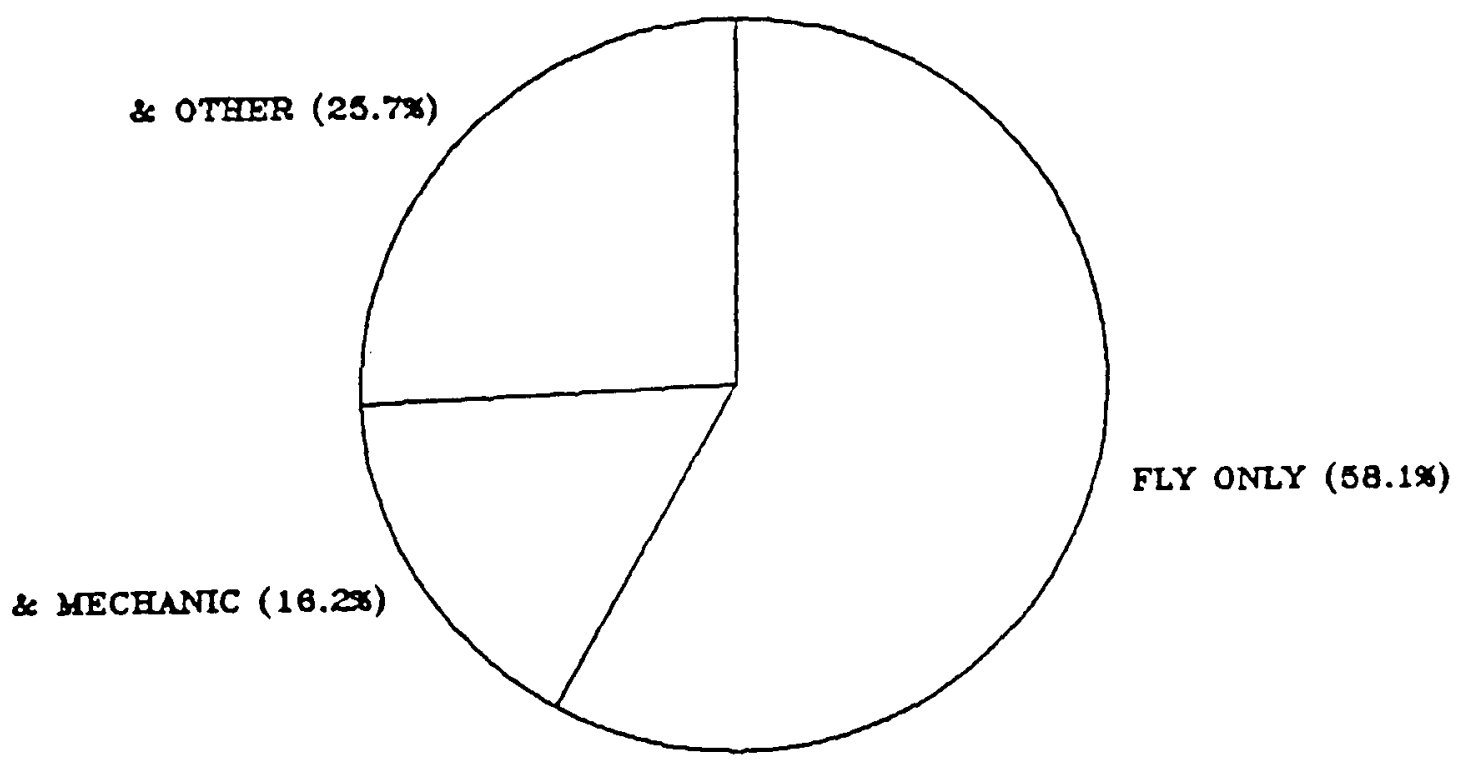


Corporate flight departments vary greatly in size, flight time and numbers of pilots available for hours flown. This diversity undoubtedly affects these choices. While initially it would seem cost effective for pilots who wait for several hours per day to have other duties, this is often impractical and may impinge on scheduling and possibly on the pilot's attention to flight concerns. The argument can be made that pilots who tily- only will base flight decisions only on flight conditions thus resulting in greater safety. Business pressures to produce through sales, or reports, etc. cauld potentially affect pilot duties and decisions. A combination of an A\&P and pilot certificate is very attractive to corporations. The mechanic certificate allows a cross-check of maintenance performed, better troubleshooting and problem descriptions, greater familiarity with the limits and capabilities of aircraft systems. The mechanic certificate is a plus for one already a pilot. A common problem for management becomes one of the right seat pilot/mechanic hired primarily as a mechanic wanting to be a fulltime captain.

Management Incentives for Pilots. In response to "What incentives are offered to pilots to keep them with the company?" respondents stressed salary, shares, vacation, increased control over schedule, fringe benefits, and miscellaneous other incentives.

\section{Management Incentives}

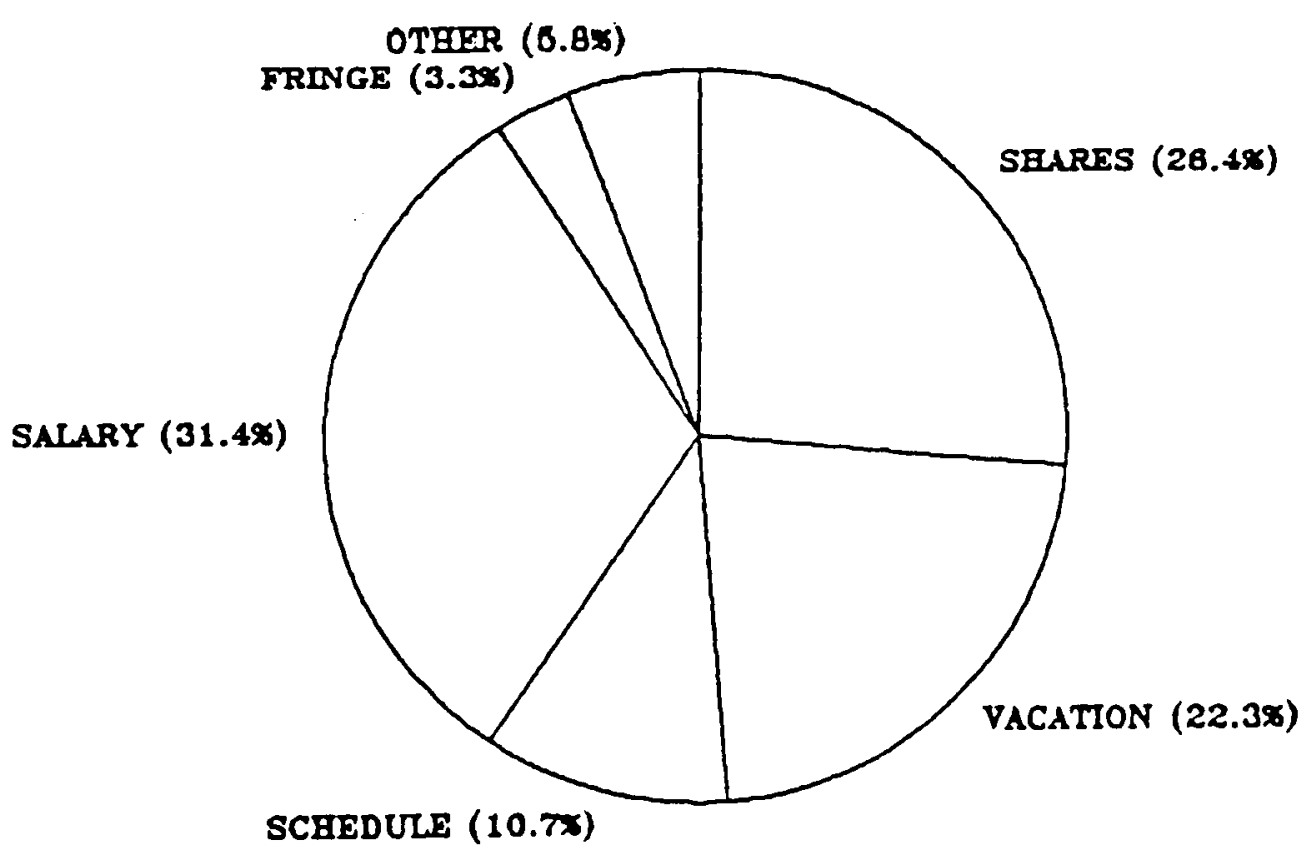


The high percentage of those offering shares in the company obviously would reinforce company loyalty as would increased input to schedules and company policy (one example from the "other" category).

\section{Areas of respondent educational concern}

In response to questions soliciting topics for seminars and for the course, respondents provided a long list of areas of concern. When compiled and organized responses can be categorized as Communication, Management, and Other. Although not directly mentioned in the survey, communication elicited the greatest number of responses. Within "Communication," the following were identified as needs for continued education and improvement of skills: written and spoken communication, interpersonal, leadership, organizational, personnel relations, public relations, and cockpit resource management. "Management" topics include overall financial management, cost analysis, goal setting, cost center management, budgeting, time and resource management. "Other" includes hijacking and terrorism, aircraft maintenance, safety, dispatch and scheduling, and airport operations.

These items were solicited by open-ended, non-directive questions. Therefore the recurrent appearance of the same topics and themes across the diverse respondents indicates a pervasive concern in the industry.

\section{Conclusion}

The survey reveals a high degree of job satisfaction, an interest in increasing skill and performance in communication and management, and a willingness to assist others in preparation of careers in corporate aviation. Certainly, this interest and willingness of those established in the business to cooperatively reach out to assist the future aviation professionals of tomorrow is a credit to the corporate aviation industry.

The survey indicates a high level of company loyalty among corporate representatives. Mutual respect is evident among co-workers, supervisors, and employees. The adherance to the highly rated home company falters in the face of the major airlines market as perceived by corporate pilots. The allure of the major airlines slot as more or less ideal continues despite the changes in that branch of the industry.

A useful and informative extension of this introductory work would be a comparison of the lifestyle/workstyle of the two aviation branches with an attempt made to identify the basis for career preference by the pilots. The impact of early entry of younger, less experienced pilots into airlines positions upon the long term interests of corporate aviation can be speculated, but is not yet clear. It may well be time for corporate marketing 
experts to identify motivational keys that will attract the best possible pilots for the industry.

In order to incorporate their wealth of long term experience in the field, this survey was addressed to an experienced group of Chief Pilots and Managers. The views of these individuals well established in the field may differ from those of new pilots entering the market. Any additional work should address designated age and experience groups in both fields. 


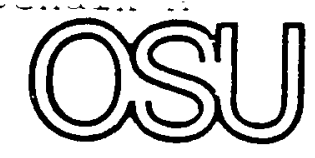

\section{The Ohio State University}

Corporate Flight Department Survey

Please indicate: Chief Pilot____ Dept. Manager Both

Number of aircraft for which responsible:
$1-5$
$6-10$
$11-15$
16-more

Number of personnel for whom responsible:
$1-5$
$6-10$
$11-15$
16-more

Flight Certificates: None

Commercial

ATP

Mechanic Certificates: None

Airframe

Powerplant

A I

Flight time: None

$3001-\overline{50} \overline{0} \overline{0}$

under 1500

$1500-3000$

Your age: $23-35$

$36-50$ 5001 -more

66 -more

Your sex: Male

Female

Is your company a 135 certificate holder? Yes

No

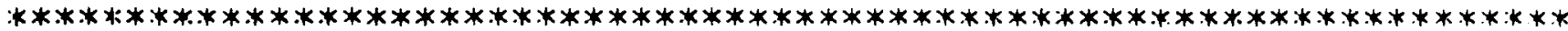

Pleasie rate each of the following. Compared with other corporations operating flight departments you would rank yours:

Salary.

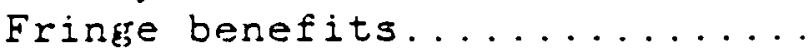

Schedule.

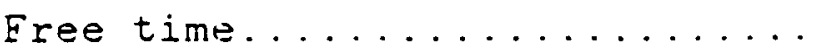

Adequate rest between trips...

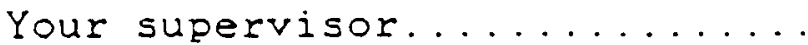

Your employees.

Your coworkers.

Job stability.

Aircrait types.

Aircraft typeraft main

Aircraft cost of operations....

Recurrency training.

Autonomy.

Your company overall..........

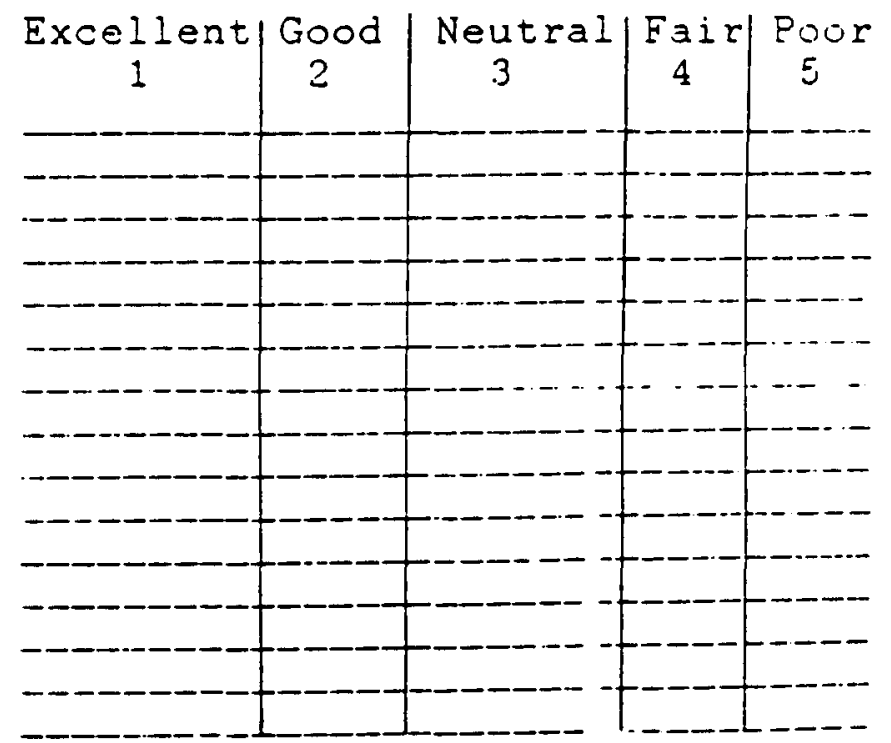


Please rate your position compared with your perceptions of a similar position with a major airlines.

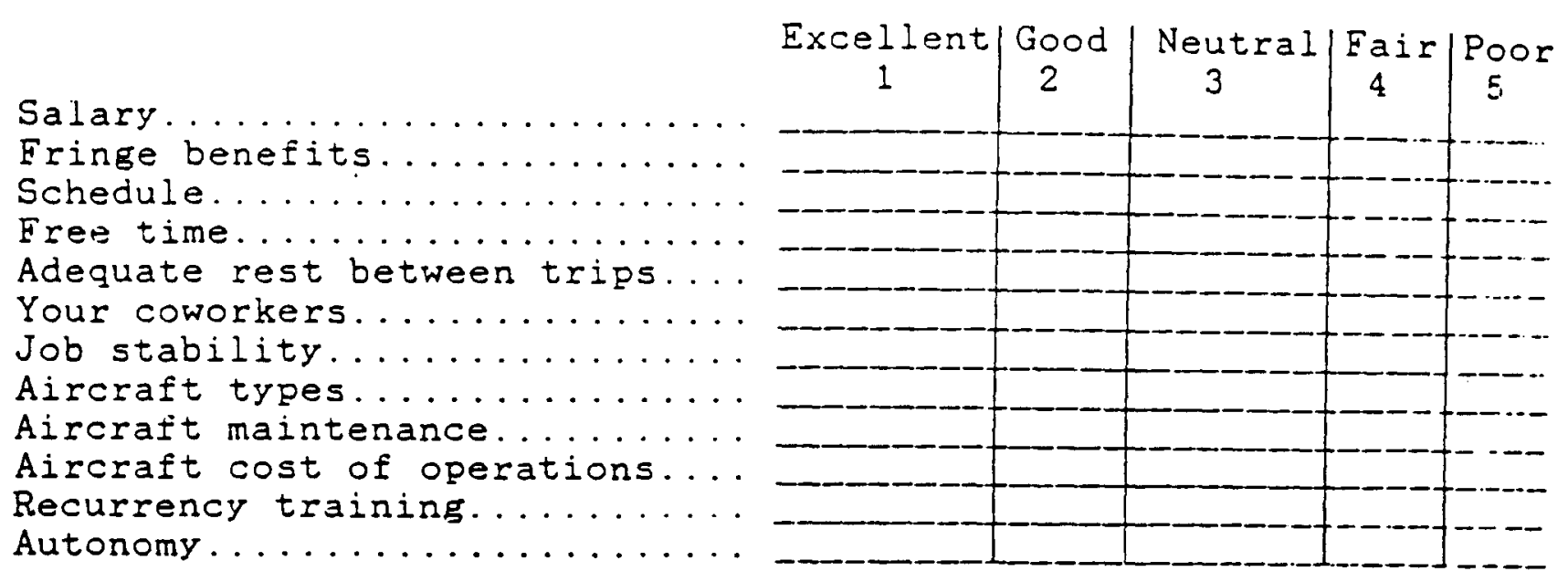

\section{If you are working primarily as a pilot answer the following:}

Do you believe that your job is endangered by legitimate no-go decisions?

Yes Sometimes No

Are you considering another flying job? Yes_._._. No N____ If YES, why?

Are you considering flying for an airlines? Yes..._._._._._._._._. If YES, why?

Do the managers and executives in your corporation have a realistic grasp of your job?
Yes
No

Do the managers and executives consider the flight department as -.- an integral component of business operations, or

- as an unnecessary convenience subject to budget cuts.

Managers of flight departments:

Do your pilots have a clear understanding of the department's position in the organizational structure of the company?

Yes No.

Do you want pilots who:

fly only

hold flight and mechanic certificates

can work in other capacities for the company 
What incentives are offered to pilots to keep them with the company?

shares in the company_____ increased vacation

increased control over schedule higher salary

other

Is your department organized as a profit center? Yes_._._. No

Rank criteria used to determine whether staff take the company plane or fly commercial airlines?

cost ___ executive's time____ commercial accessibility of destination ___ prestige ___ public relations

marketing impact of use of private plane

other

Maintenance is performed in-house or farmed-out based on: type of maintenance required _-___ cost complexity_____ relative time to complete other

\section{Both pilots and/or managers:}

Would you attend a workshop on organizational management and communication designed especially for corporate flight departments and led by individuals with practical experience?

Yes No

If YES, list two topics you believe to be most useful. 1 .

2 .

What would you recommend that we include in a course on Corporate Flight Departments for undergraduate aviation students that would be of the MOST value for them?

Please use the back of this sheet for any additional comments.

Optional:

Name

May we contact you for further assistance based on your training and practical experience?

Yes No 